\title{
New Aspects in Quality and Biofunctionality of Foods
}

\section{First Symposium of the Vienna Research Platform of Nutrition and Food Sciences (VRPNFS)}

April 25, 2008, Vienna, Austria

\section{Contents}

Introduction

Oral Presentations

Antioxidants/Oxidative Stress

Abstracts 01-05

Cell Immunity/Inflammation/Nutrition and Genetics

Abstracts 06-010

Food Quality/Analytics

Abstracts 011-015

Further Topics

Abstracts 016-O20

Posters

Abstracts P1-P27

Author Index 


\section{Nutrition\& Metabolism}

\section{New Aspects in Quality and Biofunctionality of Foods}

First Symposium of the Vienna Research Platform of Nutrition and Food Sciences (VRPNFS)

The 'Vienna Research Platform of Nutrition and Food Sciences' (VRPNFS) was established in June 2007 and is also one initiative of the Faculty Focus 'Biofunctionality of Foods' of the Faculty of Life Sciences, University of Vienna.

The Platform comprises so far more than 15 different Departments/Institutes within five Universities (University of Vienna: Faculty of Life Sciences with Departments of Nutritional Sciences and Pharmacy and Faculty of Chemistry; Technical University: Institute of Chemical Engineering, Natural Products and Food Chemistry; University of Veterinary Medicine: Department of Veterinary Public Health; Medical University: Institute of Cancer Research and Institute of Medicinal Chemistry; University of Natural Resources and Applied Life Sciences: Department of Food Science and Food Technology) thereby including the Key Scientists dealing with Nutrition and Food Research in the Area of Vienna.

This Meeting is the first initiative of the Platform and should be the kick-off for further activities and collaborations.

Presentations of this one-day Symposium (20 oral, over 40 posters) are grouped in the following topics:

- Antioxidants and Oxidative Stress

- Cell Immunity/Inflammation/Nutrition and Genetics

- Food Quality/Analytics

- Further Topics of Nutrition and Food Research

The organisers of this event would like to thank the University of Vienna for facilitating this research activity and the Publishing House Karger for accepting to disseminate the outcome of the Symposium in Annals of Nutrition and Metabolism.

Vienna, April 2008

For the Participants

I. Elmadfa

K-H. Wagner

\section{KARGER}

Fax +41613061234

E-Mail karger@karger.ch

www.karger.com 


\section{Nutritionat \& Metabolism}

\section{Antioxidants/Oxidative Stress}

\section{1}

Relation of Exhaled NO, the Total

Antioxidant Capacity and Airway Inflammation in Childhood Atopic Asthma

\author{
E. Fabian', L.A. Réthy ${ }^{2,3}$, P. Pölöskey², L. Kósa², \\ 1. Elmadfa ${ }^{1}$
}

${ }^{1}$ Department of Nutritional Sciences, University of Vienna, Austria; ${ }^{2}$ Svábhegy National Institute for Pediatrics,

Budapest, ${ }^{3}$ National Institute for Child Health, Budapest, Hungary

Background/Aim: In asthma, a chronic airway inflammation disease, the interaction of endogenously generated reactive oxygen species and nitric oxide (NO) can have a variety of deleterious effects within the airways and may probably cause oxidative stress in the circulation. Therefore, the objective of this study was to investigate the relationship between the extent of airway inflammation, Total Antioxidant Capacity (TAC) and lipid peroxidation in children suffering from atopic asthma.

Methods: 35 asthmatic ( $=\mathrm{AG}$, age: $10 \pm 3 \mathrm{y})$ and 21 healthy (= CG, age: $9 \pm 4 y$ ) children participated in this study. The volume of fractionated exhaled $\mathrm{NO}\left(\mathrm{FE}_{\mathrm{NO}}\right)$ was measured with NIOX Nitric Oxide Test System (Aerocrine AB, Sweden). TAC was determined photometrically, malondialdehyde (MDA) using HPLC.

Results: Compared to the healthy controls, asthmatic children exhaled a significantly $(\mathrm{p}<0.001)$ higher mean volume of $\mathrm{FE}_{\mathrm{NO}}$, had significantly elevated plasma levels of MDA $(p<0.001)$, but significantly lower values of TAC $(\mathrm{p}<0.01)$. This resulted in a significant positive correlation of the airway inflammation marker $\mathrm{FE}_{\mathrm{NO}}$ and the lipid peroxidation product MDA (AG: $r=0.475, p<0.01$; CG: $\mathrm{r}=0.551, \mathrm{p}<0.05)$ and in a significant negative relationship of $\mathrm{FE}_{\mathrm{NO}}$ and TAC (AC: $\mathrm{r}=-0.384, \mathrm{p}<0.05 ; \mathrm{CC}: \mathrm{r}=-0.683, \mathrm{p}<0.01$ ) in both, asthmatic and healthy children.

Conclusion: The results of this investigation indicate that systemic oxidative stress is related and an important consequence of airway inflammation in childhood atopic asthma.

\section{2}

\section{Antioxidative and Antimutagenic Effects of Bile Pigments - Novel in vitro and in vivo Data}

K.-H. Wagner ${ }^{1}$, A. Bulmer ${ }^{2}$

${ }^{1}$ Department of Nutritional Sciences, University of Vienna, Vienna, Austria; ${ }^{2}$ School of Molecular and Microbial

Sciences, University of Queensland, Brisbane, Australia

Bile pigments, including bilirubin and biliverdin, are endogenous compounds belonging to the porphyrin family of molecules. In the past, bile pigments and bilirubin in particular were thought of as useless by-products of heme catabolism. However, in the past years, research probing the physiological relevance of bile pigments has been mounting, with evidence to suggest bile pigments possess significant antioxidant and anti-mutagenic properties.

In the AMES Test anti-mutagenic effects of the bile pigments were observed in the presence of various mutagens and the anti-mutagenic effects appeared independent of the strain tested (TA 98, 100, 102). For TNF-one induced genotoxicity, bilirubin was most effective, whereas for 2-aminofluorene biliverdin showed the highest anti-mutagenic effects. Antioxidant testing in the TA102 strain revealed bile pigments could effectively inhibit the genotoxic effect of $\mathrm{t}-\mathrm{BuOOH}$ induced oxidative stress.

In vivo, individuals with Gilbert's syndrome (GS) have increased circulating bilirubin levels and a reduced prevalence of cardiovascular disease (CVD). In order to investigate this link individuals with GS and controls, matched for age, height and weight, were assessed for plasma antioxidant status. Individuals with GS had significantly elevated unconjugated bilirubin $(\mathrm{p}<0.001)$ increased trolox equivalent antioxidant capacity $(p=0.035)$ and ferric reducing ability of plasma $(\mathrm{p}=0.024)$. The lag phase of serum oxidation was significantly longer in the GS group ( $p=0.020)$.

In summary, individuals with GS have an increased circulating antioxidant status and an improved resistance to serum oxidation which may partially explain their reduced prevalence of CVD.

\section{KARGER}

(C) 2008 S. Karger AG, Basel

Fax +41613061234

E-Mail karger@karger.ch

www.karger.com
Accessible online at: www.karger.com/anm 


\section{3}

\section{The Hypoxia Paradox: Modulation of the HIF Response by Oxidative and Nitroxidative Stress by Vitamin C}

\section{H. Laggner, M.K. Muellner, S.M. Schreier, M. Moser,}

H. Goldenberg

Department of Medical Chemistry, Medical University of Vienna, Center of Physiology and Pathophysiology, Vienna, Austria

Background/Aims: HIF-1 $\alpha$ represents the oxygen-regulated subunit of the transcription factor HIF-1, which adapts cells to low oxygen conditions (hypoxia). Under normoxic conditions, HIF-1 $\alpha$ is continuously degraded by the ubiquitin proteasome system.

In the present study, we investigated the effects of vitamin $\mathrm{C}$, one of the major antioxidants in the human body, on HIF- $1 \alpha$ protein stabilization induced by nitric oxide (NO) and oxidized lipoproteins (oxLDL) during normoxia and the influence on proteasomal activity in human endothelial cells from umbilical cords (HUVECs) and THP-1 macrophages.

Methods: HIF- $1 \alpha$ protein was detected by Western blot analysis. Proteasomal activity was followed fluorimetrically by cleavage of AMC from S-LLVY-AMC. Vitamin C was assayed by HPLC and electrochemical detection.

Results: Vitamin $\mathrm{C}$ diminished the stabilization of HIF-1 $\alpha$ protein during hypoxia $\left(1 \% \mathrm{O}_{2}\right)$ in a concentration dependent manner. NO and oxLDL induced HIF- $1 \alpha$ protein accumulation in HUVECs under normoxic conditions, and this was counteracted by loading the cells with vitamin C. Significant inhibition of proteasomal activity was observed by physiologically relevant concentrations of NO, and again, vitamin $\mathrm{C}$ diminished this inhibitory effect.

Conclusion: These findings underline a possible function of vitamin $\mathrm{C}$ as a relevant modulator of NO- and oxLDL-mediated signaling in the vascular system.

\section{4}

\section{Austrian Red Wines and Their Effects on Endothelial Nitric Oxide Synthase}

\author{
O. Donath ${ }^{1}$, C.A. Schmitt 1 , R. Eder², G. Reznicek, \\ V.M. Dirsch ${ }^{1}$ \\ 'Department of Pharmacognosy, University of Vienna, \\ Vienna, ${ }^{2}$ Federal College and Research Institute for \\ Viticulture and Pomology, Klosterneuburg, Austria
}

Red wine polyphenol extracts (RWPE) are known to enhance the release of nitric oxide from endothelial cells. Resveratrol seems to partly contribute to this effect by increasing endothelial NO-synthase (eNOS) expression [1]. The identity of further major active components, however, still remains elusive.

To systematically approach the aim of active substance identification we selected 60 representative wines from Austria and quantified their principal components. Seven samples outstanding in specific components were selected for bio-assay guided fractionation using
EA.hy926 endothelial cells and the $\left[{ }^{14} \mathrm{C}\right] \mathrm{L}$-arginine $/\left[{ }^{14} \mathrm{C}\right] \mathrm{L}$-citrulline conversion assay measuring eNOS activity. Wines were applied either as tenfold concentrate or fractionated by a polystyrene column into the first eluate ('FE') and the red wine polyphenol extract ('RWPE'). The tenfold concentrates of the seven samples revealed differences in eNOS activity which correlated with their total polyphenol contents indicating that the polyphenol content plays an important role for the measured eNOS activity. On the other hand, 'RWPE'-fractions tested in equal concentrations $(600 \mu \mathrm{g} / \mathrm{ml})$ differed in their eNOS activating activity suggesting that also the polyphenol pattern is crucial for the activity. The 'FE'-fractions were completely inactive. Further fractionations of the RWPE will show what group of compounds is responsible for eNOS activation.

\section{Reference}

1. Räthel TR, Samtleben R, Vollmar AM, Dirsch VM. J Hypertens 2007; 25:541-549.

\section{5 \\ Evaluation of Antioxidant Properties of Plant Extracts}

\section{G. Kroyer}

Institute of Chemical Engineering, Natural Products and Food Chemistry, University of Technology, Vienna,

Austria

Recent research in food science has focused on plant food components which act as antioxidants and free radical scavengers. In this regard, the content of total polyphenols in commonly consumed herbal teas and the evaluation of their potential antioxidant properties might be of great significance.

Water extracts of the herbal teas rooibos tea, maté tea, peppermint tea, mallow tea and chamomile tea were prepared according to practical usage. Total polyphenols were analyzed according to the FolinCiocalteu method. The antioxidant and radical scavenging capacity was evaluated by the DPPH radical scavenging method (EC ${ }_{50}$, ARP).

All the herbal tea extracts showed considerable amounts of polyphenols $(\mathrm{mg} / \mathrm{g})$ with the highest content in rooibos tea (315) followed by maté tea (151), peppermint tea (93), mallow tea (52) and chamomile tea (50). Correspondingly, remarkable anti-radical power (ARP) was observed in the herbal tea extracts in the order rooibos tea $(138)>$ maté tea $(113)>$ peppermint tea $(118)>$ chamomile tea (19) $>$ mallow tea (12).

According to this study herbal tea consumption would be helpful in maintaining and promoting health. Furthermore, herbal tea extracts could be regarded as effective natural antioxidant additives for food products and as functional dietary food supplements.

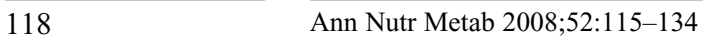

New Aspects in Quality and

Biofunctionality of Foods 


\section{Cell Immunity/Inflammation/ Nutrition and Genetics}

\section{6}

\section{Relationship of Immune Stimulation and Anti-/Oxidative Imbalance following Daily Yoghurt Consumption}

\section{Elmadfa, A.L. Meyer, E. Fabian}

Department of Nutritional Sciences, University of Vienna, Austria

Background/Aims: Probiotic bacteria are known to influence humans in relation to specific immune functions. Considering the involvement of free radicals in immunological processes the objective of this study was to evaluate the effects of probiotic and conventional yoghurt on immunological functions and anti-/oxidative parameters in young humans.

Methods: After a preadjustment phase of $7 \mathrm{~d}$, female volunteers consumed $100 \mathrm{~g} / \mathrm{d}$ of probiotic (PG: $\mathrm{n}=17$ ) or a conventional fermented milk product (CG: $\mathrm{n}=16$ ) for $14 \mathrm{~d}(\mathrm{~T} 1-\mathrm{T} 2)$ and $200 \mathrm{~g} / \mathrm{d}$ for another 14d (T2-T3). A wash-out phase lasting 14d followed.

Cytokines were measured by ELISA and Cytometric Bead Array, the Total Antioxidant Capacity (TAC), activities of erythrocyte superoxide dismutase (SOD), glutathione peroxidise (GSH-Px) and catalase (CAT) were analyzed photometrically, malondialdehyde (MDA) and conjugated dienes (CD) by HPLC.

Results: During the period of daily yoghurt intake (T1-T3) the production of proinflammatory cytokines (interleukin (IL)- $1 \beta$, tumour necrosis factor (TNF)- $\alpha$ and interferon (IFN)- $\gamma$ ) increased significantly $(p<0.05)$ in both groups. The alterations of immune functions in this period (T1-T3) were accompanied by a significant decline of TAC values (PG and CG: $p<0.001$ ), GSH-Px and CAT activities (PG: $p<0.001)$ and a significant increase of MDA (PG: $\mathrm{p}<0.01$ ) and CD (PG: $p<0.001$; CG: $p<0.01$ ). The activity of SOD remained constant throughout the study in both groups. Differences observed between the groups were not significant.

Conclusion: These results indicate that daily consumption of both, probiotic and conventional yoghurt, induces the stimulation of several immune functions probably leading to an anti-/oxidative imbalance in healthy humans.

\section{7}

\section{Characterization of Environmental and Nutritional Influences on DNA Methylation and Epigenetic Regulation of Gene Expression}

R. Thaler, V. Sagl, A. G. Haslberger

Department of Nutritional Sciences, University of Vienna, Vienna, Austria

There is increasing evidence of the determinant role of the environment, including nutrition, on the expression of many genes related to health. Polymorphisms and epigenetic regulation including a gene hypermethylation has been shown to alter gene expression. During ageing the DNA total methylation level declines, whilst some gene promoters tend to be hypermethylated. Additional mechanisms at the histone and siRNA level also contribute to the epigenetic regulatory system.

Several diet compounds are implicated in the DNA-methylation pathway. Vitamin B12 plays a central role as co-factor in the folate mediated remethylation of homocysteine to methionine which is further activated to S-adenosylmethionine (SAM), the methyl donor for DNA methylation.

We investigated the methylation-dependent epigenetic regulation of the MnSOD gene, DNA total methylation, expression of telomerase and DNA methyltransferases in cell lines and mucosal swabs of subjects consuming different diets and of different ages

DNA methylation and gene expression are analyzed by Bisufite Genomic Sequencing PCR and real time PCR respectively. For DNA global methylation ELISA techniques are used.

Results of the present study demonstrated a significant increase in expression of MnSOD mRNA in young vegetarian subjects (20-30 years) compared with omnivores of the same age. Increased MnSOD expression correlated with a $\mathrm{CpG}$ demethylation in the promoter region of the gene in the vegetarian group.

\section{8 \\ Nutrition and Cancer: Glucose and Amino Acids in Apoptosis Control}

W. Bursch, A. Karwan, M. Mayer, J. Dornetshuber, R. Schulte-Hermann

Department of Medicine I, Institute of Cancer Research, Research Unit Toxicology and Prevention, Medical University of Vienna, Austria

Nutrition is known to be involved in the pathogenesis of many diseases incl. (liver) cancer. The causative nutritional factors, however, along with their interaction with liver tumor promoter are not well understood. Accumulating evidence suggest that dietary factors (including polyunsaturated fatty acids, glucose, amino acids) may regulate gene expression/cell signalling independently of hormones, possibly acting through specific nutrient 'sensors'. Our in vivo studies on the regulation of rat hepatocyte proliferation and apoptosis revealed that the lack of glucose or AA blocks DNA synthesis and 
favours apoptosis. Here we report on a newly established human hepatoma cell line HCC-1.2 (Grasl-Kraupp et al. submitted) exhibiting the following features: (1) high sensitivity towards the anti-proliferative and pro-apoptotic action of TGF- $\beta 1,(2)$ apoptosis is mediated via the intrinsic pathway as demonstrated by caspase analysis, (3) glucose and AA-withdrawal exert an additive effect to the pro-apoptotic action of TGF- $\beta 1$, all of which agree with our in vivo observations on liver growth regulation. Questions concerning the signalling pathways involved are tackled by inhibitor experiments (wortmannin, LY294002, rapamycin). Taken together, HCC-1.2 cells meet well with prerequisites for further in vitro-studies to elucidate the mode of action of liver tumor promoter, along with their interaction with nutritional factors.

\section{9}

\section{Interaction of Nutritional Fatty Acids with Peroxisome Proliferator Activated Receptors in Colorectal Tumor Cells}

\section{Röhrl, U. Kaindl, B. Marian}

Department of Medicine 1, Div. Institute of Cancer Research, Medical University Vienna, Vienna, Austria

A high fat diet is among the major risk factors for developing colorectal cancer by disturbing the growth regulation of colorectal epithelial cells. The underlying mechanisms are manifold and not yet completely understood. Possible cellular targets are the Peroxisome Proliferator Activated Receptors (PPAR) that act as nuclear receptors for lipid mediators e.g. prostaglandins and hydroxyeicosatetraenic acids. They are ligand-dependent transcription factors that control genes mediating lipid metabolism but also affect growth control and inflammation. Their deregulation has been implicated in colorectal carcinogenesis.

We have investigated activation of PPAR $\gamma$ and $\delta$ by endogenous mediators and studied the impact on growth and viability. In addition PPAR-dependent expression of target genes related to colon carcinogenesis using reporter gene assays, RT-PCR and ELISA. Our results show induction of apoptosis by PPAR $\gamma$ - but not PPAR $\delta$-agonists. Activators of both PPARs stimulate expression of cyclooxygenase-2 and vascular endothelial growth factor. These genes control the angiogenetic switch in colonic polyps on which colon carcinogenesis depends. Nutritional fatty acids were inactive or weak PPAR-agonists, but their hydroperoxides have been shown to activate both PPARs indicating that oxidized fatty acids may exert a protumorigenic effect mediated by PPARs in colorectal tumor cells.

\section{0 \\ Influence of Dietary lodine Concentration and lodine Source (Sodium lodide vs. Sodium lodate) on lodine Concentration in Different Tissues of Fattening Pigs and on Thyroid Specific Gene Expressions}

\author{
V. Wagner ${ }^{1}$, W. Windisch 1 , K. Schedle 1 , O. Li1', S. Swoboda ${ }^{2}$, \\ T. Ettle 1 \\ 'Department of Food Science and Technology, Division of \\ Animal Food and Nutrition, University of Natural Resources \\ and Applied Life Sciences, Vienna, ${ }^{2}$ Department of Forest- \\ and Soil Sciences, Institute of Soil Science, University of \\ Natural Resources and Applied Life Sciences, Vienna, \\ Austria
}

An experiment with pigs was conducted to study the influence of dietary iodine concentration (400 and $4000 \mu \mathrm{g}$ iodine $/ \mathrm{kg}$ ) and iodine source (potassium iodide and potassium iodate) on tissue iodine, thyroid hormones and thyroid specific gene expression, growth performance and carcass characteristics. Supplementing the diets with $4000 \mu \mathrm{g} \mathrm{I} / \mathrm{kg}$ had a negative influence $(\mathrm{p}<0.01)$ on feed conversion ratio, without influencing the concentration of the thyroid hormones in the serum. PCR-analysis revealed a significant down regulation of NIS (sodium iodine symporter) in thyroid and kidney of animals fed diets supplemented with 4,000 $\mu \mathrm{g} \mathrm{I} / \mathrm{kg}$. Moreover, supplementing the diets with $4,000 \mu \mathrm{g} \mathrm{I} / \mathrm{kg}$ significantly increased the iodine content in muscle, liver, kidney, thyroid gland, blood and fatty tissue compared to a dietary addition of $400 \mu \mathrm{g} \mathrm{I} / \mathrm{kg}$; however, the magnitude of this dose-depended increase varied among the tissues. The analysed iodine concentration in muscle meat of about 25 and $47 \mathrm{ng}$ $\mathrm{I} / \mathrm{kg}$ DM confirms a statement of the EFSA [1], indicating that pork contributes only marginally to the overall iodine intake in men, consuming standard diets.

\section{Reference}

1. EFSA: Opinion of the scientific panel on additives and products or substances used in animal feed on the request from the commission on the use of iodine in feeding stuffs. EFSA J 2005;168:1-42. 


\section{Food Quality/Analytics}

\section{1}

\section{Sensor Systems for Detecting Bioactive Species} from Molecules, Viruses up to Entire Cells

P.A. Lieberzeit, M. Jenik, R. Schirhagl, A. Seifner, K. Seidler, B. Najafi, P. Grillberger, A. Biedermann, F.L. Dickert

Department of Analytical Chemistry and Food Chemistry, University of Vienna, Vienna, Austria

Good-value, easy-to-use analytical techniques are essential for modern life sciences. One strategy is chemosensors based on artificial recognition materials. Compared to antibodies, they have long-term ruggedness and multiple re-usability. Molecular imprinting into highly cross-linked polymers has proven highly suitable to achieve this goal: a polymer receptor is prepared in the presence of the analyte-to-be determining geometrical and chemical features of the final cavities via self-organization for analytes ranging from small molecules to entire cells. On QCM, imprinted materials e.g. lead to sensor layers distinguishing caffeine and xanthene, respectively. The same can also be achieved with different proteins (trypsin, insulin, globulins).

Another possibility is detecting viruses, because their size (some $10 \mathrm{~nm}$ ) currently prevents rapid detection. TMV-imprints are capable of reversibly including them from complex matrixes (e.g. plant sap). Towards the Human Rhinovirus (HRV), they are 10,000 times less selective due to geometry (TMV: rod of $300 \mathrm{~nm}$ length, $18 \mathrm{~nm}$ diameter; HRV: icosahedral, diameter $30 \mathrm{~nm}$ ).

Imprinted materials are also chemically very selective, as they can distinguish e.g. between HRV serotypes or even entire cells. They lead to the blood-group selective detection of erythrocytes both between the main blood groups, but also subgroups (A1, A2).

\section{2 \\ Determination of Food Allergens by Real- Time Polymerase Chain Reaction}

\section{Cichna-Markl \\ Department of Analytical and Food Chemistry, University of Vienna, Vienna, Austria}

Food allergies pose an increasing health problem, predominantly in industrialized countries. Some food allergens are known to be very potent causing particularly severe reactions with a high risk of life threatening anaphylaxis in sensitised persons. The only preventive strategy for allergic patients is to strictly avoid food containing the certain allergens. In order to facilitate the identification of allergenic ingredients in foodstuffs, the European Commission established a list containing 14 specified allergenic foods which must be indicated in the list of ingredients including sesame, nuts and lupine (Directive 2006/142/EC). Highly selective and sensitive analytical methods are necessary to verify if allergen containing products are labelled in compliance with the regulations and to enable the detection of socalled hidden allergens.

The paper critically discusses the potential of real-time polymerase chain reaction (real-time PCR) in food allergen analysis and gives an overview of PCR methods developed in our group: singleplex real-time PCR methods enabling the detection of either sesame, almonds or lupine and duplex real-time PCR assays to simultaneously detect sesame/hazelnut or almonds/hazelnut in food.

\section{3 \\ New Strategies for Selective Sample Clean- Up Based on Immunological Methods for Determination of Deoxynivalenol in Food and Feed Samples}

\author{
M. Cichna-Markl' ', Z. Brenn-Struckhofova', C. Böhm², \\ E. Razzazi-Fazeli \\ ${ }^{1}$ Department of Analytical and Food Chemistry, University \\ of Vienna, Vienna, ${ }^{2}$ Department of Veterinary Public \\ Health, Institute of Nutrition, University of Veterinary \\ Medicine, Vienna, Austria
}

One of the most important steps in the analysis of mycotoxins is the sample preparation prior to analysis by chromatographic methods or enzyme immunoassays. The purpose of this study was to apply different strategies to reduce the cost of the analysis of the mycotoxin deoxynivalenol (DON). One of the strategies was the development of re-usable immunoaffinity columns by entrapping anti-DON antibodies in the pores of a silicate matrix using the sol-gel method. Different column parameters were optimized during the development of the method. The sol-gel immunoaffinity columns are very selective and comparable to commercial immunoaffinity columns for the determination of DON in food and feed samples. The major advantages compared to the commercially available DON and ZON immunoaffinity columns are their simple and inexpensive preparation, high storage stability and re-usability. The method was applied to the analysis of maize, wheat and spaghetti samples for DON with detection limits (LOD, S/N = 3) of 240, 200 and $207 \mathrm{ng} / \mathrm{g}$, and recoveries of 83, 99 and $97 \%$, respectively.

In the second strategy immunofiltration in combination with ultrafiltration was applied in order to enrich DON. After development, optimisation and characterisation of this clean-up method using DON standard solutions, the applicability was investigated for sample pre-treatment of maize samples. Immunoultrafiltration resulted in HPLC chromatograms with analyte peaks being baseline separated from remaining matrix peaks. Validation of the whole analytical method was carried out with maize reference material. 


\section{4 \\ Monitoring of Ethanol Consumption Markers in Human Urine}

W. Bicker ${ }^{1}$, M. Lämmerhofer ${ }^{1}$, T. Keller ${ }^{2}$, R. Schuhmacher ${ }^{3}$, R. Krska ${ }^{3}$ W. Lindner ${ }^{1}$

${ }^{1}$ Christian Doppler Laboratory for Molecular Recognition Materials, Department of Analytical and Food Chemistry, University of Vienna, Vienna, ${ }^{2}$ IFFB Department of Forensic Medicine and Neuropsychiatry, University of Salzburg, Salzburg, ${ }^{3}$ Christian Doppler Laboratory for Mycotoxin Research, Department IFA Tulln, University of Natural Resources and Applied Life Sciences, Tulln, Austria

Background: Ethanol abuse poses a threat for our public health system. Alcohol consumption monitoring is important in fields like forensics, psychiatrics, and workplace monitoring. The ethanol phase II conjugates ethyl glucuronide (EtG) and ethyl sulfate (EtS) are specific and more sensitive markers for recent alcohol consumption than the parent compound. Besides, ethyl phosphate (EtP) was also suggested to serve as a marker. The high polarity of EtG, EtP, and EtS makes analytical method development particularly challenging.

Methods: A liquid chromatography - tandem mass spectrometry method utilising a novel mixed-mode reversed phase / weak anion exchange column was developed and applied to the analysis of urine samples (low-dose drinking study with $0.2 \mathrm{~g} \cdot \mathrm{kg}^{-1}$ bw ethanol, postmortem specimens).

Results: In the post-mortem samples levels of EtG (max. 1,384 $\mathrm{mg} \cdot \mathrm{L}^{-1}$ ) and $\mathrm{EtS}\left(\max .220 \mathrm{mg} \cdot \mathrm{L}^{-1}\right.$ ) each lacked correlation with urinary ethanol concentration. EtP concentrations were in direction much lower and did not exceed $8.3 \mathrm{mg} \cdot \mathrm{L}^{-1}$. Likewise, in the drinking study elimination kinetics could be monitored over $24 \mathrm{~h}$ for EtG and EtS but not for EtP.

Conclusions: Determination of polar analytes becomes more and more important for many branches of life sciences and novel analytical tools may help improving fields like biomonitoring and metabolomics.

\section{5 \\ Detection of the Illegal Addition of Soybean Protein to Meat Products by Two-Dimensional HPLC and Tandem Mass Spectrometry}

\section{A. Leitner ${ }^{1}$, F. Castro-Rubio ${ }^{2}$, M.L. Marina ${ }^{2}$, W. Lindner ${ }^{1}$ \\ ${ }^{1}$ Department of Analytical Chemistry and Food Chemistry, University of Vienna, Vienna, Austria; ${ }^{2}$ Departamento de Química Analítica, Facultad de Química, Universitad de Alcalá, Alcalá de Henares, Madrid, Spain}

The addition of soybean proteins to food products to facilitate processing and/or improve consistency is strongly regulated. Currently, detection of soybean proteins mainly relies on immunochemical methods that have drawbacks such as limited specificity. Here, we have used a gel-free proteomics approach to identify marker proteins in meat products of different origin that can be used for the detection of the illegal addition of soybean protein during food production. Meat extracts were first fractionated by perfusion liquid chromatography on the protein level and fractions of interest were digested with trypsin. The resulting peptides were then analyzed by nanoflow HPLC-tandem mass spectrometry.

Data analysis was complicated by the high degree of sequence homology between the different variants of the major soybean proteins, glycinins and $\beta$-conglycinins. Only a fraction of the total number of identified peptides were unique for a given variant or subunit of a variant requiring optimization of the experimental design to ensure their reliable discrimination. Glycinin G4, subunit A4, was consistently found in spiked meat products from beef, pork, chicken and turkey and can be considered a marker protein for soybean protein addition. This enables rapid testing using targeted mass spectrometric approaches such as Multiple Reaction Monitoring.

\section{Further Topics}

\section{6 \\ Professional Probiotics: A New Generation of Nutritional Supplements}

\author{
H. Viernstein, F.M. Unger \\ Department of Pharmaceutical Technology and \\ Biopharmaceutics, Faculty of Life Sciences, University of \\ Vienna, Austria
}

Interest is growing in probiotic foods, nutritional supplements and pharmaceuticals. Strains of microorganisms used for probiotic preparations comprise mostly lactobacilli and bifidobacteria, but strains of Escherichia coli, Enterococcus faecium and Saccharomyces boulardii are also used. Application forms range from fermented milks such as yoghurts and kefirs to powders, tablets, capsules and oily suspensions for use as supplements and pharmaceuticals. Of the motivations for consumption of probiotics, economically most significant is the desire for general health maintenance and well-being. However, significant growth is predicted for those probiotics which we designate here as professional probioticals. They can be categorized into nutritional supplements and pharmaceuticals. Probiotic nutritional supplements are increasingly successful at correcting specific floral imbalances that fall short of actual disease but predispose individuals to infections of the oral cavity, the intestinal tract, or the vagina. Beyond such prophylactic applications, probiotics continue to be investigated as therapeutics or therapeutic adjuncts in conditions such as infantile colic, chronic inflammatory bowel diseases, and conditions that constitute sequelae of bowel surgery. While a measure of success has been achieved in specific indications, further progress of professional probiotics is expected through discovery and combination of more potent bacterial strains, combinations with prebiotics, and specific pharmaceutical formulations. 


\section{7 \\ Development and Use of Methods for the Detection of DNA-Protective and Anticarcinogenic Components of Human Foods}

\section{S. Knasmüller}

Department of Medicine I, Institute of Cancer Research, Medical University of Vienna, Vienna, Austria

In the last years we attempted to develop and use methods, which enable the identification of chemopreventive properties of dietary factors. The models comprise the use of human liver cell lines which possess drug metabolising enzymes similar to those of primary cells, animal experiments in which preneoplastic lesions in colons and livers are used as endpoints and DNA-migration experiments in inner organs and in peripheral blood cells. The later approach can also be used in human intervention trails.

By combination of different models it is possible to draw conclusions concerning the potential cancer protective effects of dietary components in humans. Examples for successful applications of these methods are investigations with gallic acid, which showed that this phenolic compound is an extremely potent antioxidant in humans and also protects against DNA-damage in inner organs. Furthermore we also showed that it is possible to prevent the formation of ROS induced preneoplastic lesions in the liver of laboratory rodents. Similar results where obtained with Brussels sprouts and we could show in this case by use of proteomic analyses of blood cells that changes of the protein expression patterns of lymphocytes seen in a intervention trail are controversial to those caused by oxidative stress.

\section{8 \\ Use of Fiber Instead of Laxative Treatment in a Geriatric Hospital to Improve the Wellbeing of Seniors}

\author{
B. Sturtzel, I. Elmadfa \\ Department of Nutritional Sciences, University of Vienna, \\ Vienna, Austria
}

Background: In nursing homes constipation and laxative-use are common. Current studies link both to weight-loss and poor nutritional status (MNA-Screening). Bowels are also affected by fibers, particularly when fluid management is all-right.

Aim: It was examined whether addition of oat-bran to common oral diet can reduce laxative-use and improve bodyweight (nutritional status).

Methods: A controlled-blind-parallel intervention trial among 30 inhabitants of a geriatric hospital aged 57-100 years. Including criteria: oral food intake, laxative-therapy, excluding criteria: parenteral and enteral feeding, surgeries in the gastro-intestinal tract, drugs that shorten or lengthen the passage through the gut, risk of aspiration, swallowing troubles.

The fiber-group $(\mathrm{n}=15)$ received $7-8 \mathrm{~g}$ oat-bran/d for 12 weeks. The control-group $(n=15)$ received the hospitals habitual diet. Data collection: Bodyweight was taken at week 1- 6 -12. Data of laxativeuse, fluid and energy intake and MNA-Screening were recorded.

Results: MNA-Screening resulted in 7.4 (1.5) points (mean $\pm \mathrm{SD}$ ); fluid-intake was $1,800( \pm 320) \mathrm{ml} / \mathrm{d}$; energy intake was $1,180( \pm 330)$ $\mathrm{kcal} / \mathrm{d}$. Laxatives decreased by $59 \%$ in the fiber-group and increased in the control-group by $8 \%$. Bodyweight remained constant in the fibergroup but decreased in the control group $(p=0.002)$.

Conclusion: Fiber supplementation is a convenient alternative to laxatives and helps stabilizing bodyweight even when MNAScreening resulted in low points.

\section{9}

Biogenic Amines in Meat and Meat Products

\section{F. Bauer, P. Paulsen}

Institute of Meat Hygiene, Meat Technology and Food

Science, University of Veterinary Medicine, Vienna,

Austria

Biogenic amines are formed in meat and meat products as a consequence of spoilage or as undesired by-products of a principally desired microbial activity during fermentation of raw sausages.

Mainly putrescine, cadaverine and tyramine and rarely also histamine is formed during storage and spoilage in unprocessed meat. Hugh amounts of amines being a health risk could only be determined after meat putrefacted recognisable for the consumer.

In heated products the occurrence of biogenic amines reflects the hygienic status of the raw material.

In the case of raw sausages the situation is quite different. It cannot be excluded that some of the micro-organisms which are predominant during fermentation (first of all Lactobacteria) have the ability to decarboxylate amino acids. In fact, commercial starter cultures are controlled regarding their ability to form biogenic amines. Still ubiquitareous flora might be able to form biogenic amines if not suppressed by starters. These micro-organisms generally are not able to metabolise proteins, the substrates for decarboxylation have to be already present in the raw material. As small amounts of biogenic amines cannot be avoided, an excessive formation of amines indicates that the raw material used for production was not in a hygienically perfect condition.

\section{0 \\ Resveratrol: Impact of Metabolism on Anticancer Activity}

W. Jäger

Department of Clinical Pharmacy and Diagnostics, University of Vienna, Vienna, Austria

Cancer, next only to heart diseases, is the second leading cause of deaths in the United States of America and many other nations in the world. Chemoprevention in combination with anticancer treatment is therefore crucial for reducing the incidence of disease and mortality. Resveratrol (3,5,4'-trihydroxy-trans-stilbene) produced by several plants, berries, and fruits and found mainly in the skin of grapes and 
red wine demonstrates antiproliferative property against various human cancer cell lines and xenografts. Oral bioavailability in humans, however, is very low based on based on extensive glucuronidation and sulfation in the intestine and liver. In order to determine whether metabolism of resveratrol also occurs in tumor cells and whether biotransformation has any impact on cytotoxicity, metabolism experiments were conducted with hormone-dependent ZR-751 and hormone-independent MB-MDA-231 human breast cancer cells. Along with resveratrol, it was possible to identify one metabolite, namely, resveratrol-3-O-sulfate in both cell lines. Its concentration in the cytoplasm and culture medium was 5.4-9-fold higher in ZR-75-1 cells than in MDA-MB-231 cells, concomitant with a 3.1- fold higher $\mathrm{IC}_{50}$ value in the ZR-75-1 cell line (74 $\mu \mathrm{M}$ compared to $38 \mu \mathrm{M})$. By using RT-PCR, expression of sulfotransferase (SULT)1A1 mRNA, but not of other SULTs investigated, showed a close correlation with resveratrol 3-O-sulfate formation which was particularly high in ZR-75-1 and very low in MDA-MD-231 cells. Further experiments with MDA-MB-231 cells stably transfected with SULT1A1 demonstrated an increased cellular formation of resveratrol sulfate together with an increased $\mathrm{IC}_{50}$ value of $54 \mu \mathrm{M}$. In conclusion, we demonstrate that SULT1A1-based biotransformation reduces the anticancer activity of resveratrol in breast cancer cells, which must be considered in humans following oral uptake of dietary resveratrol as a chemopreventive agent. 


\section{Nutrition\& Metabolism}

\section{P1 \\ Irradiation of Sage, Thyme and Oregano. Impact on Polyphenols, Tocopherols and Antioxidative Properties in the Ames Test}

\section{S. Brandstetter, C. Berthold, B. Isnardy, S. Solar, I. Elmadfa}

Department of Nutritional Sciences, Faculty of Life Sciences, University of Vienna, Vienna, Austria

Background: The study aimed to assess possible differences between antioxidaitve and antimutagenic properties of irradiated (gamma-radiation of $10 \mathrm{kGy}$ ) and non-irradiated herbal extracts. Methanol and chloroform extracts of sage, thyme and oregano simulated water and lipid soluble fraction, respectively. 1:1-mix extract demonstrated herb as a whole.

Methods: The Ames test with Salmonella typhimuirum tester strains TA98, TA100, TA102 was applied as preincubation assay with and without an exogenous metabolic activation system. Total antioxidative capacity was assessed using TEAC, total polyphenols using Folin-Ciocalteau-reagent and tocopherols using HPLC.

Results: Antioxidative effects in the Ames test were stronger seen in nearly all samples using a metabolic activation system; without the methanol and mixed extract some prooxidative effects were recorded, chloroform extracts acted clearly antioxidative though. Antimutagenicity was more considerable in TA98 than in TA100 but partly not detected. Impact of irradiation was minimal in bacteria test systems and TEAC, polyphenol and tocopherol analysis of irradiated sample and control were indiscriminate.

Conclusion: Summing up results, $\gamma$-irradiation of $10 \mathrm{kGy}$ may not influence antioxidative properties of dried sage, thyme and oregano; effects alter due to contained constituents. Lipid soluble fraction was most effective and seems to be crucial for antioxidative properties of examined herbs.

\section{P2}

\section{Determination of Bisphenol $A$ in Food by Sol-Gel Immunoaffinity Chromatography, HPLC and Fluorescence Detection}

\section{Cichna-Markl \\ Department of Analytical and Food Chemistry, University of Vienna, Vienna, Austria}

Bisphenol A (BPA) is a so-called endocrine disruptor, being able to cause weak estrogenic effects by binding to the estrogen receptor. However, BPA serves as a monomer in the production of epoxy resins which are used as protective linings in metal food and beverage cans as well as wine storage vats. Several studies have shown that BPA can migrate from epoxy linings into canned food. Using wine simulants, Larroque et al. [1] estimated a worst case BPA concentration of 650 $\mathrm{ng} / \mathrm{ml} \mathrm{BPA}$ in wine caused by BPA leakage from vat coatings.

In order to get realistic data on BPA exposure due to wine consumption, in the present paper BPA concentrations were determined in 60 wine samples. 31 samples were obtained from Austrian vintagers, 29 samples were bought in local markets. The analytical method involved sol-gel immunoaffinity chromatography, HPLC and fluorescence detection.

In almost all wine samples very low levels of BPA were found, ranging from 0.1 to $2.1 \mathrm{ng} / \mathrm{ml}$ in white wine and from non-detectable ( $\mathrm{LOD}=0.1 \mathrm{ng} / \mathrm{ml}, \mathrm{S} / \mathrm{N}=3$ ) to $1.2 \mathrm{ng} / \mathrm{ml}$ in red wine samples. BPA concentrations were far lower than the worst-case estimate reported by Larroque et al [1].

\section{References}

1. Larroque M, Brun S, Blaise A. Sciences des Aliments 1989;9:517.

P3

\section{Age Related Modification of Enzymatic Antioxidants Affects Lipid Peroxidation in Elderly People}

\section{E. Fabian, I. Elmadfa}

Department of Nutritional Sciences, University of Vienna, Austria

Background/Aim: Superoxide dismutase, (SOD) glutathione peroxidase (GSH-Px) and catalase (CAT) are the three main enzymes controlling biological effects of reactive oxygen species including lipid peroxidation.

The objective of this study was to characterize changes in the enzymatic antioxidant defence system and the generation of lipid peroxidation products in relation to different age periods of elderly people.

Methods: A total of 102 subjects (45 males, 57 females) were recruited for this investigation. The participants were divided into three groups: A $(70>75 y ; n=48), B:(75>80 y ; n=35), C:(\geq 80 y$; $\mathrm{n}=19)$. The activities of the erythrocyte antioxidant enzymes SOD, GSH-Px and CAT were determined by photometrical methods, malondialdehyde (MDA) and conjugated dienes (CD) using HPLC.

Results: The analyses of antioxidant enzyme activities revealed an age related significant decrease of SOD $(\mathrm{A}>\mathrm{C} / \mathrm{B}>\mathrm{C}$; $\mathrm{p}<0.01)$, CAT $(\mathrm{A}>\mathrm{C} ; \mathrm{p}<0.05)$ and of GSH-Px $(\mathrm{A}>\mathrm{C}$; $\mathrm{p}<0.05)$, accompanied by a significant increase of plasma MDA $(\mathrm{A}<\mathrm{C} / \mathrm{B}<\mathrm{C} ; \mathrm{p}<0.01)$ and $\mathrm{CD}(\mathrm{A}<\mathrm{C} / \mathrm{B}<\mathrm{C} ; \mathrm{p}<0.01)$ levels. The alterations of GSH-Px/CD (A: $\mathrm{r}=-0.397, \mathrm{p}<0.01 ; \mathrm{B}$ : $\mathrm{r}=-0.289, \mathrm{p}<0.05 ; \mathrm{C}: \mathrm{r}=-0.533, \mathrm{p}<0.01)$ and CAT/MDA (A: $r=-0.344, B: r=-0.431, C: r=-0.370 ; p<0.05)$ were found to be significantly associated in all observed groups.

\section{KARGER}

Fax +4161306 1234

E-Mail karger@karger.ch

www.karger.com
(C) 2008 S. Karger AG, Basel

Accessible online at: www.karger.com/anm 
Conclusion: The findings of this study indicate that an age related decrease of antioxidant enzyme activities accompanied by increased lipid peroxidation may reflect an anti-/oxidant imbalance in elderly people.

\section{P4 \\ Adsorption of Mycotoxins on Lactic Acid Bacteria}

S. Fuchs ${ }^{1 *}$, S. Knasmüller ${ }^{2}$, G. Sontag ${ }^{1}$

${ }^{1}$ Department of Analytical and Food Chemistry, University of Vienna, Vienna, ${ }^{2}$ Department of Medicine I, Institute of Cancer Research, Medical University of Vienna, Vienna,

Austria

The decrease of the biological effective concentration of two mycotoxins, ochratoxin A (OTA) and patulin (PAT) which frequently occur in human foods, by adsorption of lactic acid bacteria (LAB) was investigated. The decline of the mycotoxin concentration by 30 different LAB-strains in liquid medium was determined by high performance liquid chromatography coupled with UV- or fluorescence detection. Two highly effective strains were identified. L. acidophilus caused a decrease of OTA concentration by $95 \%$ and B. animalis reduced PAT levels by $80 \%$. To proof, that the decrease of mycotoxin concentration by LAB from liquid medium results in a decline of their toxic properties, micronucleus (MN) assays with a human derived hepatoma cell line (HepG2) were conducted. A decrease of 39-59\% of OTA and PAT induced MN-formation with the two most effective strains was observed. Furthermore, the inhibition of the cell division rates by the toxins was significantly reduced. These findings indicate that certain LAB strains are able to adsorb the two mycotoxins. For this reason they display the possibility, that they may be useful to protect humans or animals against the adverse health effects of these compounds.

P5

\section{Analysis of Lignans in Foodstuffs}

\section{E. Gerstenmeyer, S. Reimer, H. Schwartz, G. Sontag* \\ Department of Analytical and Food Chemistry, University of Vienna, Vienna, Austria}

Lignans are a group of polyphenolic phytoestrogens, which can be found e.g. in seeds, nuts, cereals, fruits and vegetables. They have gained increasing interest because of their potential positive biological effects.

In our study four different sample preparation methods for the lignans were applied to deconjugate the glycosidic and esterfied compounds: extraction with ethanol/water $(70: 30, \mathrm{v}: \mathrm{v})$ in the ultrasonic bath or with accelerated solvent extraction (ASE) without any further treatment, extraction with ethanol/water (70:30) in the ultrasonic bath or with ASE followed by enzymatic hydrolysis (Helix pomatia juice), alkaline extraction (methanol/water, $0.3 \mathrm{M} \mathrm{NaOH}$ ) and alkaline extraction in the ultrasonic bath followed by enzymatic hydrolysis.
The diluted extracts were separated on reversed phase columns (ACE $3 \mathrm{C} 18100 \times 2.1 \mathrm{~mm}$ or $150 \times 3.0 \mathrm{~mm})$ using different gradients (HPLC-MS: Mobile phase A: $0.1 \%$ acetic acid, mobile phase B: $0.1 \%$ acetic acid in acetonitirile; HPLC-CEAD: Mobile phase A: acetonitrile/ $0.01 \mathrm{M}$ sodium acetate adapted to $\mathrm{pH} 4.8,(18: 82, \mathrm{v}: \mathrm{v})$, mobile phase B: acetonitrile/ $0.01 \mathrm{M}$ sodium acetate adapted to $\mathrm{pH} 4.8$ (50: $50, \mathrm{v}: \mathrm{v})$ and the lignans were detected by ESI-Mass spectrometry in the negative mode using characteristic $[\mathrm{M}-\mathrm{H}]^{-}$masses and fragments of the lignans and by coulometric electrode array detection (CEAD) at potentials between +200 and $+700 \mathrm{mV}$.

In sesame the lignans pinoresinol, lariciresinol, isolariciresinol, hydroxymatairesinol, sesaminol and sesamolinol could be identified by mass spectrometry: The content of the compounds varied between $1.5 \mathrm{mg} / \mathrm{kg}$ (isolariciresinol) and $230 \mathrm{mg} / \mathrm{kg}$ (pinoresinol). In rye the main lignan is syringaresinol but also lariciresinol could be detected.

\section{P6 \\ Phenolic Acids in Honey \\ E. Gruenauer*, S. Fuchs, G. Sontag \\ Department of Analytical and Food Chemistry, University of Vienna, Vienna, Austria}

Phenolic acids are one of the most important phenolic compounds occurring in plants, which exhibit anticarcinogenic, anti-inflammatory, anti-atherogenic and antithrombotic activity due to the function as an antioxidant. The content and composition of phenolic acids in honey depend on the floral source used by bees to collect nectar. Therefore they can be an analytical instrument to differentiate between the various sorts of unifloral honey. In this study a new extraction method using ASE (Accelerated Solvent Extraction) was established. Different parameters like temperature and extraction time were tested and evaluated. Working with the optimal conditions (temperature: $100^{\circ} \mathrm{C}$, extraction time: 2 cycles, each 5 minutes) a recovery between approximately 70 and $100 \%$ could be obtained. The analysis was performed by HPLC with coulometric detection. Numerous honeys of various sorts were tested and compared by analyzing ten phenolic acids: gentisic acid, protocatechuic acid, 4-hydroxybenzoic acid, 4-hydroxyacetic acid, caffeic acid, vanillic acid, syringic acid, pcumaric acid, 2-hxdroxybenzoic acid and ferulic acid. The distribution pattern of phenolic acids allows to differentiate between different sorts of honey.

\section{P7}

\section{Effects of Different Tocopherol-Emulsions on Catalase, Glutathion Peroxidase and Superoxide Dismutase in Erythrocytes}

\author{
D. Hinterberger, I. Elmadfa \\ Department of Nutritional Sciences, Faculty of Life \\ Sciences, University of Vienna, Austria
}

Objective: Vitamin $\mathrm{E}$ is the most important lipid soluble antioxidant in human blood. Superoxide dismutase (SOD), glutathion 
peroxidase (GSH-Px) and Catalase (CAT) are the main antioxidative enzymes, mediating defence against oxidative stress in cells.

The objective of this study was to investigate if stepwise enhancing the concentration of vitamin $\mathrm{E}$ up to the twofold physiological level in human blood has an effect on the redox status in erythrocytes.

Methods: Ten healthy women (age: $27.8 \pm 2.7$ ) were recruited for this study. 12 tocopherol emulsions $\left(\mathrm{E}_{1-12}\right)$ containing different concentrations and/or mixes of $\alpha$-, $\gamma$ - and $\delta$-tocopherol were tested. The emulsion/blood mixtures and whole blood (served as control) were incubated for two hours at $37^{\circ} \mathrm{C}$. Enzymatic activities of erythrocyte SOD, CAT and GSH-Px were measured photometrically at the beginning and after the incubation.

Results: During the incubation of the tested emulsion/blood mixtures the mean enzymatic activities of SOD, CAT and GSH-Px did not alter significantly. Even regarding the different mixtures of Vitamin $\mathrm{E}$ emulsions $\left(\mathrm{E}_{1-12}\right)$ no significant variations in the catalytic activities of these enzymes could be demonstrated.

Conclusion: These results indicate that different forms and concentrations of vitamin $\mathrm{E}$ do not have an influence on the regulation of the erythrocyte antioxidant enzyme defence in stress condition.

\section{P8 \\ Development of a Competitive Enzyme Linked Immunosorbent Assay (ELISA) to Determine Potentially Allergenic Sesame in Food}

\section{FT. Husain, M. Cichna-Markl}

Department of Analytical and Food Chemistry, University of Vienna, Vienna, Austria

Numerous papers report on the severity of allergic reactions caused by the consumption of sesame seeds, including life threatening anaphylaxis. In the past, sesame (Sesamum indicum) allergy was only common in Eastern countries. Recent papers, however, indicate that allergic reactions to sesame have become more frequent in European countries.

The present paper presents a competitive enzyme linked immunosorbent assay (ELISA) to determine potentially allergenic sesame in food. Anti-sesame antibodies were produced by immunizing a hen with the protein fraction extracted from sesame. For developing the ELISA, the IgY fraction was isolated from the egg yolk by ammonium sulphate precipitation.

In the development of the ELISA, several parameters had to be optimized, e.g. the concentrations of the primary and the secondary antibody, the coating antigen concentration and the coating temperature. The optimized ELISA proved to be specific for sesame and did not show any cross-reactivity with peanuts, hazelnut, walnut, Brazil nut, poppy seed, wheat, rye, oat, chocolate, honey and several other products. The influence of different food matrices on the recovery of sesame was investigated by analysing food samples which had been previously spiked with defined amounts of sesame.
P9

\section{Sensor Measuring Methods for Characterising Food-Relevant Systems and Their Degradation}

\section{Jenik, A. Seifner, R. Schirhagl, K. Seidler, B. Najafi, P. Grillberger, P.A. Lieberzeit, F.L. Dickert}

Department of Analytical Chemistry and Food Chemistry, University of Vienna, Vienna, Austria

A multitude of chemical and biological sensor systems has been proposed for assessing natural samples including different transducers especially suitable for artificial recognition materials.

One is acoustic sensors, e.g. quartz crystal microbalances (QCM) or surface acoustic wave (SAW) resonators. Their main advantage is the ability to directly detect analyte mass. Hence, they yield a very straightforward signal independent of further physical parameters, such as extinction. Thus, it is e.g. possible to detect proteins, viruses and cells in aqueous matrices. Whereas QCM offer superior ruggedness, SAW have outstanding sensitivity due to their increased fundamental frequency. Furthermore, with QCM, the direction of the frequency shift hints on the surface mobility of the analyte cells.

Interdigital capacities also offer outstanding bioanalyte sensing abilities, because the lipid bilayer of the cell surface changes the dielectric properties of a sensor film on the electrodes. Additionally, IDC are sensitive towards rapid variations and hence allow for investigating recognition dynamics e.g. between imprinted polymers and cells via autocorrelation.

Finally, surface plasmon resonators (SPR) are also an invaluable tool in sensing: being very sensitive to changes in refractive index of their environment, they can e.g. directly assess the enzymatic reaction between trypsin or pepsin with covalently surface-immobilized peptides.

\section{P10 \\ Evaluating the Nutritional Composition of Different European Ready-to-Eat Meals}

\author{
S. Kanzler, M. Manschein, A. Gruber, K.-H. Wagner \\ Department of Nutritional Sciences, University of Vienna, \\ Vienna, Austria
}

Background: The importance of ready-to-eat (RTE) meals is steadily growing in the last years. Therefore, one aim of the 'Double Fresh' Project is to evaluate the nutritional composition of European RTE meals.

Materials and Methods: Altogether 13 RTE meals (5 various packages of each meal) of 7 different producers (Northern Europe, Benelux Countries, Central Europe) were prepared according to the instructions and the nutritionally important parameters total energy (bomb calorimeter), fat $\left(\mathrm{ASE}^{\circledR} 100\right)$, carbohydrates (calculated), fatty acid pattern (GC-FID), dietary fibres (enzymatically) and salt (titration) were analysed.

Results: Total energy of the tested RTE meals ranged from 294 to $828 \mathrm{kcal} /$ portion, fat from 4.6 to $33.8 \mathrm{~g} /$ portion and carbohydrates from 40.6 to $143.3 \mathrm{~g}$ /portion. Regarding the fatty acid pattern, the polyunsaturated fatty acids varied strongly from 1.0 to $11.1 \mathrm{E} \%$. Only two meals reached the recommendation of $9 \mathrm{~g}$ dietary fibres per 
portion. The salt content ranged from 3.5 to $6.8 \mathrm{~g} /$ portion, which is considerably more than recommended ( $>1.8 \mathrm{~g} /$ portion).

Conclusion: The energy content of most of the tested RTE meals is appropriate for adults with a physical activity level of 1.6, but the nutritional compositions need to be optimized especially regarding fat, fatty acid pattern, dietary fibres and salt.

\section{P11}

Tocopherol and Essential Fatty Acid Status of Erythrocytes in Vegetarians and Omnivores

\section{Kornsteiner, I. Elmadfa \\ Department of Nutritional Sciences, Faculty of Life Sciences, University of Vienna, Vienna, Austria}

Background/Aims: The objective of the study was to analyse the tocopherol status and the essential fatty acid composition in vegetarians and omnivores.

Methods: The study included 98 adults of both genders, of which 23 were omnivores (consume all foods), 25 vegetarians (consume no meat, but eggs, or dairy products), 37 vegans (consume no meat, poultry, fish, eggs, or dairy products) and 13 semi-omnivores (mostly lacto-vegetarian, sometimes fish and poultry) from Austria.

Both, determination of tocopherol in erythrocytes with HPLC and haemolysis test were carried out. The essential fatty acids were analysed with GC in sphingolipids, phosphatidylcholine, phosphatidylserine and phosphatidylethanolamine.

Results: The analysed $\alpha$-tocopherol content $(\mu \mathrm{g} / \mathrm{g}$ erythrocyte packed cells) were $0.75 \pm 0.30$ (omnivores), $1.07 \pm 0.37$ (vegetarians), $0.96 \pm 0.40$ (vegans) and $1.02 \pm 0.26$ (semi-omnivores). All dietary groups showed a normal haemolysis $(<10 \%)$.

The fatty acid analyses demonstrated no significant differences in the total saturated, monunsaturated, polyunsaturated and $n-6$ fatty acids. Vegans and vegetarians had significantly reduced portions of $\mathrm{C}$ 20:5n-3, C 22:5n-3 and C 22:6n-3 in phosphatidylcholine, phosphatidylethanolamine and partly phosphatidylserine.

Conclusion: The study showed no tocopherol deficiency in the investigated dietary groups. However, the biochemical improvement of C 20:5n-3, C 22:5n-3 and C 22:6n-3 should be a main nutritional target in vegetarians and vegans.

\section{P12}

\section{Toxicological Effects of Oxyphytosterols on HepG2 Cells}

\author{
K. Koschutnig ${ }^{1}$, S. Kemmo², A.-M. Lampi², V. Piironen², \\ K.-H. Wagner ${ }^{1}$ \\ ${ }^{1}$ Department of Nutritional Sciences, University of Vienna, \\ Austria; ${ }^{2}$ Department of Applied Chemistry and \\ Microbiology, University of Helsinki, Finland
}

During the past few years phytosterols (plant sterols) have become a focus of interest because of their serum cholesterol lowering properties; consequently an increasing number of products fortified with plant sterols have been introduced to the market.

Due to their structural similarities with cholesterol, phytosterols are expected to undergo analogous chemical reactions, including oxidation. While health implications of cholesterol oxidation products (COPs) have already been extensively documented, information on phytosterol oxidation products (POPs) is rather scarce. First data show similar toxicity like cholesterol oxides. However, more investigations are necessary.

Therefore, the purpose of the present study was to analyse the effects of several oxidation products of $\beta$-sitosterol on HepG2 cells. Further a possible connection with reactive oxygen species was investigated. Additionally the development of a method to determine the uptake of POPs in the cells was included in this study. POP-concentrations in cells and corresponding media were measured by normalphase high-performance liquid chromatography with ultraviolet absorption and evaporative light scattering detection.

The results clearly indicate that the tested oxidation products caused a significant reduction in cell numbers $(p<0.05)$. In addition concentration dependency was observed. Moreover a significant negative correlation $(\mathrm{p}<0.05)$ between absorption levels and cytotoxicity was shown.

\section{P13 \\ Sensory Properties of Commercially Available Plain Conventional and Probiotic Yogurt}

\section{B. Lahm, D. Majchrzak \\ Department of Nutritional Sciences, University of Vienna, Austria}

The health-relevant properties of probiotic yogurt are often used for sales promotion. However, the consumer preferences of the product determine ultimately its sensory quality. Therefore it was examined with a Quantitative Descriptive Analysis (QDA) whether probiotic and conventional yogurts differ according to sensory properties.

Ten trained panelists evaluated over 2 sessions the overall quality of yogurt samples by rating the intensity of sensory descriptors on a 10-unit scale from commercially available plain conventional (12) and probiotic (10) yogurts, served in a randomised order.

Consumers' preferences were determined by 50 persons applying the paired difference test for preference.

Generally, the mean overall quality score of probiotic yogurt was higher (6.1), than the one of conventional products (5.5), but the difference was not statistically significant. This finding could be attributable to the higher sweetness (3.3) and creaminess (3.6) of the evaluated probiotic yoghurt varieties in comparison to conventional products (2.8 and 3.1 respectively).

Based on the analytical and hedonic sensory evaluation, it appears that despite of some observed differences in sensory properties, there were no significant differences in consumers' preferences between probiotic and conventional yogurt. 
P14

\section{Stereoselective Determination of D- and L-Lactic Acid Profiles during Food Processing such as the Malolactic Acid Fermentation of Wine}

\section{W. Lindner, M. Lämmerhofer}

Christian-Doppler Laboratory for Molecular Recognition Materials, Department of Analytical and Food Chemistry, University of Vienna, Vienna, Austria

Numerous bacterial species are present during the vinification process and perform particular fermentation reactions. One of such processes is the malolactic fermentation (MLF) by Oenococcus oeni that may be desirable because this bacterium enzymatically converts malic acid to lactic acid which decreases wine acidity. One of the possibilities to follow and control MLF is via the stereoselective profiles of lactic acid in wine. Lactic acid is usually not found in grape must, but is present in all wines as a product of microbial activity. Both D- and L-lactic acid can be found, yet with different concentrations. D-lactic acid is found in small quantities $(100-500 \mathrm{mg} / \mathrm{l})$ due to alcoholic fermentation and other microbial processes while large amounts of L-lactic acid $(1,000-5,000 \mathrm{mg} / \mathrm{l})$ can be found in wines that have undergone malolactic fermentation which refers to the decarboxylation of the natural L-malate to L-lactate.

Several methods have been described in the literature for the determination of lactic acid enantiomers. Enzymatic methods are well established in wine industry for this purpose while chromatographic methods using chiral ligand exchange principles are less common. The former are expensive and slow, while the latter is not very robust and uses copper ions in the eluent which is harmful for HPLC instruments and environment. In the present contribution we propose a new stereoselective HPLC assay for lactic acid which is robust and environmentally friendly. Its integration into the routine HPLC analysis method of organic acids will be discussed.

\section{P15}

\section{Apple Juice as a Source of Antioxidans - Comparison of Plain and Naturally Cloudy Apple Juices}

\author{
D. Majchrzak, G. Binder \\ Department of Nutritional Sciences, University of Vienna, \\ Austria
}

At the consumption of approx. 8 litres/person/year, apple juice is one of Austria's favourite fruit juices, thus constituting an important source of antioxidans in daily nutrition apart from fruit and vegetables. The present study has been designed to compare the vitamin $\mathrm{C}$ contents, the total phenolics and the antioxidant capacity of different types of plain and naturally cloudy apple juices. Six selected commercially available cloudy and four plain apple juices were investigated. The total phenolics (PhC) and the total anioxidant capacity (TAC) were measured photometrically (PhC: Folin-Ciocalteu procedure, TAC: ABTS method). Vitamin C contents were established using RP-HPLC method.
An advantageous assessment of the cloudy apple juice in comparison to plain apple juice was observed in all examined parameters: mean $\mathrm{PhC}$ : cloudy juice $=0.6 \mathrm{~g} / \mathrm{l}$, plain juice $=0.3 \mathrm{~g} / \mathrm{l}$; mean TAC: cloudy juice $=5.6 \mathrm{mmol} /$ TroloxE $/ 1$, plain juice $=2.2 \mathrm{mmol}$ TroloxE $/ \mathrm{l}$; mean Vitamin C: cloudy juice $=16.4 \mathrm{mg} / 100 \mathrm{ml}$, plain juice $=4.9 \mathrm{mg} / 100 \mathrm{ml}$.

Generally, under the here applied criteria, cloudy apple juice could be considered to be superior to its clear counterpart. The results represent a useful tool for the industry to evaluate fruit juice processing with the focus on clarification for the development of new techniques for the production of clear juices.

\section{P16}

\section{Authentication of Ewes' Cheese by Using Isoelectric Focusing of $\gamma$-Caseins and Real-Time PCR}

\author{
H.K. Mayer*, A. Weippl, S. Mayr \\ BOKU - University of Natural Resources and Applied Life \\ Sciences, Department of Food Science and Technology, \\ Food Chemistry Division, Vienna, Austria
}

In Europe, cheese varieties made from ewes' and goats' milk are of considerable economic importance as result of widespread acceptance of traditional cheeses. However, as substitution of cows' milk for ewes', goats' and buffaloes' milk is a fraudulent practice in dairy industry, food analysts are challenged by milk species identification.

The objective of this study was the quantitative determination of cow's milk percentage in Bryndza sheep cheese. Reference samples were analyzed according to the EU reference method by isoelectric focusing. Species identification was also performed by conventional polymerase chain reaction (PCR) as well as quantitative real-time PCR using species-specific primers.

Usually, the EU reference method is performed as a qualitative technique using reference samples, which are certified with $0 \%$ and $1 \%$ of cow's milk. However, after densitometric evaluation of $\gamma$ caseins, a quantitative estimation of cow's milk percentage was obtained in mixed-milk Bryndza cheeses. PCR was shown to be a qualitative method, although a certain semi-quantitative estimation could be achieved in some cases. Real-time PCR was appropriate to determine the cow's milk percentage in mixed Bryndza cheese samples quantitatively.

However, quantitative results in adulteration control have to be understood as approximate values, and authentification of mixed cheeses still remains a challenge. 


\section{P17 \\ Conventional Fermented Milk Products May Be as Effective in Stimulating the Cellular Immune Defence in Healthy Humans as Probiotic Ones}

\author{
A.L. Meyer ${ }^{1}$, I. Elmadfa' ${ }^{1}$ M. Micksche ${ }^{2}$, I. Herbacek ${ }^{2}$ \\ ${ }^{1}$ Institute of Nutritional Sciences, University of Vienna, \\ ${ }^{2}$ Institute of Cancer Research, Medical University of \\ Vienna, Vienna, Austria
}

Immune stimulation by lactic acid bacteria is generally acknowledged. However, it is questionable whether the heavily promoted probiotic strains are really superior to the conventional ones, consumed for centuries. A probiotic and a conventional yogurt were therefore compared with regards to their immunological effects in humans.

Thirty-three young healthy women consumed either $100 \mathrm{~g} / \mathrm{d}$ of a probiotic (L. casei DN-114001) or a conventional (L. bulgaricus and $S$. thermophilus), commercially available yogurt for two weeks, then $200 \mathrm{~g}$ for another two weeks, followed by two weeks without fermented products. Blood samples were taken before the intervention (T1), after each intake period (T2 and T3) and after the refraining phase (T4). Immune status, the expression of the activation marker CD69 on $\mathrm{CD}^{+}{ }^{+}$and $\mathrm{CD}^{+}$T-lymphocytes following mitogenic stimulation and the activity of natural killer (NK) cells against K562 target cells were determined by flow cytometry.

Cell numbers were not profoundly altered. Expression of CD69 was significantly higher following consumption of conventional yogurt (T3: $+27 \%$ on $\mathrm{CD}^{+} ;+15 \%$ on $\mathrm{CD}^{+}, \mathrm{p}<0.05$ vs. $\mathrm{T} 1$ ), showing a slight dose-effect. NK cell activity also showed a significant increase in both groups (up to $+176 \%$ in the conventional, $\mathrm{p}<0.05$ ). $200 \mathrm{~g} / \mathrm{d}$ did not cause a further increase, but the effect persisted after the cessation. Despite some diverging trends, no significant differences were seen between the groups.

Daily consumption of a conventional yogurt was as effective in stimulating cellular immunity as that of a probiotic one.

\section{P18 \\ Enhanced Antioxidant Capacity after an Ironman Triathlon}

O. Neubauer, L. Nics, N. Kern, S. Reichhold, K.-H. Wagner

Department of Nutritional Sciences, Faculty of Life

Sciences, University of Vienna, Vienna, Austria

Background/Aims: There is controversy whether the beneficial physiological effects of regular physical activity are offset by extremely demanding endurance exercise due to increased oxidative stress (OS). The present study was aimed to examine changes in OS markers as well as antioxidant status and capacity following an Ironman triathlon $(3.8 \mathrm{~km}$ swim, $180 \mathrm{~km}$ cycle, $42.2 \mathrm{~km}$ run) and whether there are indications for persistent oxidative damage and thus detrimental health consequences.

Methods: Blood samples were taken from 42 well-trained male triathletes (mean $\pm \mathrm{SD}$ : $35.3 \pm 7$ years, $\mathrm{VO}_{2}$ peak: $56.6 \pm 6.2 \mathrm{ml} \mathrm{kg}$ $\mathrm{min}^{-1}$ ) 2 days (d) before an Ironman triathlon, then immediately postrace, 1, 5 and $19 \mathrm{~d}$ later. Blood plasma was analysed for concentrations of various OS markers, nutritive and endogenous antioxidants and Trolox equivalent antioxidant capacity (TEAC).

Results: Most, but not all OS markers significantly increased in response to the Ironman, however they had returned to prerace values $5 \mathrm{~d}$ postrace. Whereas TEAC, vitamin $\mathrm{C}$, alpha-tocopherol and uric acid significantly $(\mathrm{p}<0.001)$ increased immediately postrace, concentrations of most nutritive plasma antioxidants dropped below prerace significantly $1 \mathrm{~d}$ postrace (except for vitamin $\mathrm{C}$, which did not drop significantly).

Conclusion: This study indicates that there are important training- and acute exercise-induced alterations in the antioxidant defence system in well-trained athletes that are capable to prevent long-term oxidative damage in the course of an acute bout of ultra-endurance exercise.

\section{P19 \\ Plant Oils Affect Adiponectin Levels in Type 2 Diabetics \\ E. Plasser ${ }^{1}$, H. Brath ${ }^{2}$, E. Forster ${ }^{2}$, K.-H. Wagner ${ }^{1}$ \\ ${ }^{1}$ Department of Nutritional Sciences, University of Vienna, Vienna, ${ }^{2}$ Vienna Health Center South, Vienna, Austria}

Aim: Since decreased adiponectin (Acrp30) levels are discussed as a risk factor for cardiovascular events, Acrp30-levels in type-2-diabetics (T2DM) were investigated before and after plant oil intervention.

Study design: To study the effects of PUFA-rich plant oils (pure single oil - SO; and mixed oil - MO) 92 participants (insulindependent (IDDM) and non-insulin-dependent (NIDDM)) had to consume daily three teaspoons of the respective oil. Blood samples were taken before intervention - T0, after four weeks (T1) and 10 weeks (T2) of intervention, and eight weeks after intervention - T3 and triglycerides (TG), blood glucose (BG) (both enzymatically), Acrp30 (ELISA), and insulin (RIA) were analyzed.

Results: Acrp30-levels ranged from 2.11-19.80 $\mu \mathrm{g} / \mathrm{ml}$ $(8.25 \pm 3.62 \mu \mathrm{g} / \mathrm{ml})$ at T0. At T2 a slight increase in Acrp30 was observed in all participants, the strongest increase was measured in the MO-IDDM at T1 $(7.98 \% ; \mathrm{p}=0.051)$ and MO-NIDDM at T2 $(6.98 \%, p<0.05)$ respectively. Furthermore Acrp30 was inversely associated with TG during the whole study period (T0 $\mathrm{r}=-0.45$, T1 $\mathrm{r}=-0.45, \mathrm{~T} 2 \mathrm{r}=-0.43, \mathrm{~T} 3 \mathrm{r}=-0.43, \mathrm{p}<0.01)$ and with insulin (T0 $\mathrm{r}=-0.24, \mathrm{p}<0.05 ; \mathrm{T} 1 \mathrm{r}=-0.42, \mathrm{~T} 2 \mathrm{r}=-0.29$, T3 $\mathrm{r}=-0.31, \mathrm{p}<0.01)$, whereas $\mathrm{BG}$ and Acrp30 only correlated inversely at $\mathrm{T} 1(\mathrm{r}=-0.23, \mathrm{p}<0.05)$.

Conclusion: An easy and practical intervention with few tea spoons of plant oils daily showed increasing Acrp30-concentrations which seem to have positive influence on the lipid profile in T2DM. 


\section{P20}

\section{Effects of an Ironman Triathlon on DNA Stability}

\section{S. Reichhold, O. Neubauer, K.-H. Wagner \\ Department of Nutritional Sciences, University of Vienna, Vienna, Austria}

Background: During acute and strenuous exercise the enhanced formation of reactive oxygen species can induce damage to lipids, proteins and nucleic acids. Thus, the major aim of the study was to investigate the effect of an Ironman triathlon $(3.8 \mathrm{~km}$ swim, $180 \mathrm{~km}$ cycle, $42 \mathrm{~km}$ run) on DNA stability.

Materials and Methods: Within the cytokinesis-block micronucleus cytome (CBMN Cyt) assay the number of micronuclei (MNi), nucleoplasmic bridges (NPB) and nuclear buds (Nbuds) were measured in 20 triathlets (age $32 \pm 6$ years; $\mathrm{VO}_{2}$ peak $60.8 \pm 8.8$ $\mathrm{ml} / \mathrm{kg} / \mathrm{min}$; height $182.8 \pm 6.2 \mathrm{~cm}$; weight $76.7 \pm 8.1 \mathrm{~kg}$ ) 2 days (d) before, within $20 \mathrm{~min}$ after the race, $5 \mathrm{~d}$ and $19 \mathrm{~d}$ post race.

Results: The number of $\mathrm{MNi}$ decreased $(\mathrm{p}<0.05)$ after the race. The frequency of NBP declined from $2 \mathrm{~d}$ pre race to $19 \mathrm{~d}$ post exercise $(p<0.05)$. The number of Nbuds increased after the triathlon, peaking $5 \mathrm{~d}$ post race $(\mathrm{p}<0.01)$ and decreased to basic levels $19 \mathrm{~d}$ after the race $(\mathrm{p}<0.01)$.

Conclusion: The present study suggests that an Ironman triathlon does not cause long lasting DNA damage in well trained athletes probably due to the upregulation of repair mechanisms and the increased capacity of the endogenous antioxidative system.

\section{P21}

\section{Antioxidant Status of Austrian Apprentices}

\section{P. Rust, K. Haas, I. Elmadfa}

Department of Nutritional Sciences, Faculty of Life Sciences, University of Vienna, Vienna, Austria

Background/Aims: Investigations indicate that a lower educational level in adolescence is associated with higher prevalence of health compromising behaviour like cigarette smoking, sedentary lifestyle and unhealthy eating habits. Aim of the present study was to examine the nutritional and health status of Austrian apprentices.

Methods: Blood samples were taken from 143 apprentices (68 female and 75 male; mean \pm SD: age: $17.7 \pm 1.6$ years, BMI: $23.5 \pm 3.9 \mathrm{~kg} / \mathrm{m}^{2}$ ). Blood was analysed for haematological and lipid profile, and plasma values of antioxidant vitamins as well as minerals.

Results: Although retinol intake was below the D-A-CH recommendations plasma concentrations of retinol were within the normal range in female (ø $2.91 \pm 0.9 \mu \mathrm{mol} / \mathrm{l})$ as well as in male: (Ø $3.09 \pm 0.58 \mu \mathrm{mol} / 1)$. Due to the low fruit and vegetable intake $47 \%$ of the investigated adolescents did not reach the desirable plasma level of $0.75 \mu \mathrm{mol}$ beta-carotene/1. Plasma tocopherolequivalent levels were inadequate in $3 \%$ of female (ø $22.6 \pm 4.3 \mu \mathrm{mol} / 1)$ and $6.8 \%$ of male study subjects $(\varnothing 21.1 \pm 3.7 \mu \mathrm{mol} / \mathrm{l})$. These results reflect the average vitamin $\mathrm{E}$ intake $(9 \pm 5 \mathrm{mg} / \mathrm{d})$ but are not alarming at all. But $99 \%$ of the participants had a folic acid deficiency (female: $2.9 \pm 1.0$ nmol/1; male: $3.5 \pm 1.1 \mathrm{nmol} / 1)$. The estimated apprentices ate only small amounts of plant products and folic acid intake was $78.7 \pm 30.3$ $\mu \mathrm{g} / \mathrm{d}$ on average. Serum concentrations of vitamin $\mathrm{C}$ average $106.7 \pm 26.1 \mu \mathrm{mol} / \mathrm{l}$, female apprentices $(119.91 \pm 22.79 \mu \mathrm{mol} / \mathrm{l})$ show significantly higher levels than male $(94.86 \pm 23.07 \mu \mathrm{mol} / \mathrm{l})$ $(\mathrm{p}<0.001)$.

Conclusions: Although health behaviour is not desirable (high rate of smokers, low sport activities), the antioxidant status of the examined apprentices is not too bad. Levels of carotenoids, vitamin E, and especially folic acid should be improved by higher consumption of fruit and vegetables as well as a better choice of fats and food rich in fat. Thus, national health programs should focus on young people especially lower educated like apprentices to prevent risk factors for chronic diseases in later life.

\section{P22}

\section{Interaction of Different Insoluble Dietary Fiber Sources, on Inflammatory and Cell Cycle Marker Genes in the Gastro Intestinal Tract}

\author{
K. Schedle1, M.W. Pfaffl' ${ }^{2}$,W. Windisch ${ }^{1}$ \\ ${ }^{1}$ Department of Food Science and Technology, University of \\ Natural Resources and Applied Life Sciences, Vienna, \\ Division of Animal Food and Nutrition, Vienna, Austria; \\ ${ }^{2}$ Technical University of Munich, Nutrition and Food \\ Research Center, Physiology Unite, Freising-Weihenstephan, \\ Germany
}

The study aimed to examine gastrointestinal effects of insoluble fiber using 48 piglets as animal model. Model substances tested for fiber were: wheat bran (rich in insoluble hemicellulose) and pollen from Chinese Masson pine (pinus massoniana) (rich in lignin), which were added on base of total dietary fiber to standard diets to piglets (control [no addition], wheat bran [3.0\%], pollen low [1.3\%], pollen high [2.6\%]). Each 12 animals were fed one of the 4 diets ad libitum for 5 weeks and were then slaughtered. Gastro intestinal tissue samples were immediately snap frozen in liquid nitrogen. Gene expression analyses were carried out with quantitative real time reverse transcriptase PCR. Wheat bran induced an up-regulation of NFKB in stomach and jejunum, as well as TNF alpha and TGF beta, and Caspase 3 in jejunum. No changes were observed in the ileum. Pine pollen induced down-regulation of NFkB, TNF alpha, TGF beta, Caspase 3, CDK 4 and IGF 1 in the colon as well as up-regulation of NFKB and TGF beta in mesenterial lymph nodes. Results suggest that insoluble fiber may significantly affect cell activity (proliferation, inflammation, cell cycle) along the entire digestive tract, depending on the nature of the fiber source. 


\section{P23}

\section{Copper- But not HOCl-Modified Low Density Lipoproteins Accumulate HIF-1 $\alpha$ Protein in THP-1 Macrophages Under Normoxic Conditions}

S. Schreier, M. Moser, H. Goldenberg, H. Laggner

MUW, Center of Physiology and Pathophysiology,

Department of Medical Chemistry, Vienna, Austria

Background/Aims: In the pathogenesis of atherosclerosis, accumulation of oxidatively modified low density lipoproteins (oxLDL) in macrophages lead to foam cell formation and reactive oxygen species generation. The hypoxia inducible factor- $1 \alpha$ (HIF-1 $\alpha)$ is stabilized under hypoxia. However, HIF-1 $\alpha$ is stabilized under normoxia after oxLDL treatment via redox-dependent mechanisms. The reactions inducing LDL modification in vivo are still seen controversial. In contrast to $\mathrm{CuSO}_{4}$-modified LDL, HOCl-modified LDL has been found in atherosclerotic lesions, supporting its possible role in vivo.

The aim of this study was to investigate the effect of $\mathrm{CuSO}_{4^{-}}$and HOCl-modified LDL on foam cell formation and the expression of HIF-1 $\alpha$ protein under normoxia in THP-1 macrophages.

Methods: Oxidation of LDL was induced by $10 \mu \mathrm{M} \mathrm{CuSO}_{4}$ or $1 \mathrm{mM}$ HOCl. Phorbolester-differentiated THP-1 cells were used as model for macrophages, HIF-1 $\alpha$-protein was detected by Western blot. Lipids in the cells were stained with oil red o.

Results: $\mathrm{CuSO}_{4}$ - but not $\mathrm{HOCl}$-modified LDL accumulate HIF$1 \alpha$ in THP-1 macrophages under normoxia. Moreover, $\mathrm{CuSO}_{4}$-modified LDL induce foam cell formation and lipid deposits in the cells.

Conclusion: Since $\mathrm{HOCl}$ is likely to be more relevant to modify LDL in vivo, the significance of $\mathrm{CuSO}_{4}$-oxLDL induced HIF- $1 \alpha$ accumulation in macrophages should be further investigated and discussed.

\section{P24}

Yellow Pigments in Wheat Species: Determination and Influence of Processing

\author{
S. Siebenhandl-Ehn ${ }^{1 *}$, H. Grausgruber ${ }^{2}$, F. Eticha ${ }^{2}$, \\ M. Kinner ${ }^{1}$, L. Leopold ${ }^{1}$, E. Berghofer ${ }^{1}$ \\ 1Department of Food Sciences and -technology and \\ ${ }^{2}$ Department of Applied Plant Sciences and Plant \\ Biotechnology, University of Natural Resources and \\ Applied Life Sciences, Vienna, Austria
}

With the increasing interest in the possible link between carotenoid intake from foods and health, the need for reliable data on the carotenoid content of raw materials and processed foods has become important.

The aim was to study the yellow pigment (YP) content of diverse wheat species according to ICC 152 in comparison to THF/MeOH (1:1) as solvent. Both extraction methods correlated well $(\mathrm{r}=0.96)$; the $\mathrm{THF} / \mathrm{MeOH}$ mixture resulted in up to $20 \%$ higher values. A range of 3-30 ppm YP based on dry weight was determined with highest values for einkorn wheat.

The influence of processing on the fate of YP was investigated on bread, noodles and pearled grain. First losses were observed after mixing ( $3 \mathrm{~min}$ ), followed by approx. $25 \%$ during fermentation ( $80 \mathrm{~min}$, $27^{\circ} \mathrm{C}$ ). Losses due to baking $\left(25 \mathrm{~min}, 220^{\circ} \mathrm{C}\right.$ ) remain low for the bread crumb, and were significantly higher (approx. $40 \%$ ) for the bread crust.

Cooking of pearled einkorn in excess of water for 15 min resulted in losses of up to $50 \%$. Interestingly, steaming of pearled einkorn for 15 min was considerably gentler (final loss: approx. 15\%).

These findings provide useful information for technologists and eventually extended commercial producers of value-added varieties of cereals rich in health beneficial components.

\section{P25 \\ Physiological Background of Requirement for Vitamin E}

\section{Tramp, E. Fabian, I. Elmadfa}

Department of Nutritional Sciences, Faculty of Life Sciences, University of Vienna, Vienna, Austria

Background/Aims: The objective of this total diet study was to gain further information about the vitamin-E-requirement by investigating the effect of daily intake of $\alpha$-tocopherol-equivalents $(\alpha$-TE) and unsaturated fatty acids (UFA) on vitamin-E-status in plasma of young healthy women.

Methods: During a 7-weeks lasting period four 24-hour recalls (P1/P2/P3/P4) of 3 female volunteers (age: $22 \pm 1.5 \mathrm{y}$; BMI: $20.2 \pm 2.6$ ) were collected. The meals were prepared according to the recall data to express total $\alpha$-TE. Tocopherols $(\alpha / \beta / \gamma / \delta)$ and tocotrienols $(\alpha / \beta / \gamma / \delta)$ were analyzed by HPLC, fatty acid pattern was assessed using GC, and ingested total fat by Weibull-method. In plasma, concentrations of vitamin $\mathrm{E}$ ( $\alpha$ - and $\gamma$-tocopherol) were measured by HPLC, total lipids were determined photometrically.

Results: The analysis of the prepared protocols revealed a wide intraindividual variation in the vitamin-E-consumption, the average $\alpha$-TE-intake (P1-P4) however, could be assessed as appropriate to protect the amount of consumed UFA. Plasma levels of vitamin E ( $\mu \mathrm{Mol} \alpha-\mathrm{TE} / \mathrm{g}$ total lipids) could be regarded as sufficient in all examined participants.

Conclusion: The analysis of 24-hour protocols indicated a sufficient $\alpha$-TE-intake assessed by the calculated vitamin-E/UFA ratio in the diet and vitamin-E-concentrations in plasma. Further studies have to be carried out to reevaluate and probably support these findings.

\section{P26}

\section{Alterations of the Antioxidant Enzyme Activities in Asthmatic Children}

\author{
F. Wortuba ${ }^{1}$, P. Rust' ${ }^{1}$ E. Fabian', E. Hagel ${ }^{2}$, M. Bogyi ${ }^{2}$, \\ M. Götz ${ }^{2}$ I. Elmadfa ${ }^{1}$ \\ 'Department of Nutritional Sciences, University of Vienna, \\ 2Willhelmininspital, Kinderlungenambulanz, Vienna, Austria
}

Background/Aim: Asthma is an inflammatory disorder of the airways resulting in endogenously generated reactive oxygen species that contribute to tissue injury and asthma symptomatology. 
The objective of this study was to investigate differences in the antioxidant enzyme activities in erythrocytes and the Total Antioxidant Capacity (TAC) of asthmatic and healthy children.

Methods: A total of 47 asthmatic (=AC, age: 6-18y) and 20 healthy (=CC, age: $6-18 \mathrm{y})$ children participated in this study. The activities of the erythrocyte antioxidant enzymes superoxide dismutase (SOD), glutathione peroxidase (GSH-Px) and catalase (CAT) and plasma concentrations of TAC, respectively, were determined by photometrical methods.

Results: In asthmatic children, the enzymatic activities of SOD $(\mathrm{p}<0.001)$, GSH-Px, $(\mathrm{p}<0.05)$ and CAT $(\mathrm{p}<0.05)$ were significantly decreased compared to the levels observed in healthy children. Additionally, a significant difference between the groups was also found regarding the TAC values $(\mathrm{AC}<\mathrm{CC}, \mathrm{p}<0.01)$, resulting in significant correlations of TAC/SOD (AC: $r=0.480, p<0.001 ; C C$ : $\mathrm{r}=0.510, \mathrm{p}<0.05)$, TAC/GSH-Px (AC: $\mathrm{r}=0.366, \mathrm{p}<0.01$; CC: $\mathrm{r}=0.501, \mathrm{p}<0.05)$ and TAC/CAT $(\mathrm{CC}: \mathrm{r}=0.479, \mathrm{p}<0.05)$ in the observed subjects.

Conclusion: These results indicate that childhood asthma is accompanied by an alteration of the antioxidant enzyme activities, probably due to oxidative stress in this chronic airway disease.
P27

\section{Zinc Transporter mRNA Expression during Differentiation of Caco-2 Cells}

A. Zemann', N. Brandl', H. Hammerschmid', M. Huettinger ${ }^{1}$, I. Elmadfa ${ }^{2}$

${ }^{1}$ MUW, Center of Physiology and Pathophysiology, Department of Medical Chemistry, ${ }^{2}$ Department of Nutritional Science, University of Vienna, Vienna, Austria

Background/Aims: In culture, Caco-2 cells differentiate from colonocytes to cells expressing characteristics usually linked to enterocytes of the small intestine. They are widely used to simulate drug and nutrient resorption from the intestinum. While changes in expression of many nutrient transporters during differentiation have been described, the effect on expression of transporters relevant for resorption of zinc has not been investigated yet.

Aim of this study was to investigate cytotoxicity of zinc and changes of expression levels of zinc transporters (ZnT-1, ZnT-5, ZIP1 and ZIP4) during differentiation.

Methods: MTT-assays were performed with zinc-challenged preconfluent, confluent and postconfluent Caco-2 cells. RT-PCR was used to investigate changes in expression levels of the zinc transporters during differentiation and after stimulation with $100 \mu \mathrm{M}$ zinc-chloride.

Results: Differentiated Caco- 2 cells were able to survive higher concentrations of zinc. Expression of ZIP4 and ZnT-5 was constant during differentiation, while ZIP1 expression decreased and ZnT-1 expression increased in differentiated Caco- 2 cells. Among the investigated transporters, only ZnT-1 expression was regulated by zinc stimulation.

Conclusions: These findings demonstrate that state of differentiation has an impact on zinc tolerance and expression of zinc-transporters in Caco-2 cells and has to be taken into account, when studying zinc-metabolism. 


\section{Nutrition\& Metabolism}

Bauer, F. O19

Berghofer, E. P24

Berthold, C. P1

Bicker, W. O14

Biedermann, A. O11

Binder, G. P15

Bogyi, M. P26

Böhm, C. O13

Brandl, N. P27

Brandstetter, S. P1

Brath, H. P19

Brenn-Struckhofova, Z. O13

Bulmer, A. O2

Bursch, W. O8

Castro-Rubio, F. O15

Cichna-Mark1, M. O12, O13, P2, P8

Dickert, F.L. O11, P9

Dirsch, V.M. O4

Donath, O. O4

Dornetshuber, J. O8

Eder, R. O4

Elmadfa, I. O1, O6, O18, P1, P3, P7, P11, P17, P21, P25, P26, P27

Eticha, F. P24

Ettle, T. O10

Fabian, E. O1, O6, P3, P25, P26

Forster, E. P19

Fuchs, S. P4, P6

Gerstenmeyer, E. P5

Goldenberg, H. O3, P23
Götz, M. P26

Grausgruber, H. P24

Grillberger, P. O11, P9

Gruber, A. P10

Gruenauer, E. P6

Haas, K. P21

Hagel, E. P26

Hammerschmid, H. P27

Haslberger, A.G. O7

Herbacek, I. P17

Hinterberger, D. P7

Huettinger, M. P27

Husain, F.T. P8

Isnardy, B. P1

Jäger, W. O20

Jenik, M. P9, O11

Kaindl, U. O9

Kanzler, S. P10

Karwan, A. O8

Keller, T. O14

Kemmo, S. P12

Kern, N. P18

Kinner, M. P24

Knasmüller, S. O17, P4

Kornsteiner, M. P11

Kósa, L. O1

Koschutnig, K. P12

Kroyer, G. O5

Krska, R. O14

Laggner, H. O3, P23

Lahm, B. P13

Lämmerhofer, M. O14, P14
Lampi, A.-M. P12

Leitner, A. O15

Leopold, L. P24

Lieberzeit, P.A. O11, P9

Lindner, W. O14, O15, P14

Li, Q. O10

Majchrzak, D. P13, P15

Manschein, M. P10

Marian, B. O9

Marina, M.L. O15

Mayer, H.K. P16

Mayer, M. O8

Mayr, S. P16

Meyer, A.L. O6, P17

Micksche, M. P17

Moser, M. O3, P23

Muellner, M.K. O3

Najafi, B. P9, O11

Neubauer, O. P18, P20

Nics, L. P18

Paulsen, P. O19

Pfaffl, M.W. P22

Piironen, V. P12

Plasser, E. P19

Pölöskey, P. O1

Razzazi-Fazeli, E. O13

Reichhold, S. P18, P20

Reimer, S. P5

Réthy, L.A. O1

Reznicek, G. O4

Röhrl, C. O9

Rust, P. P21, P26
Sagl, V. O7

Schedle, K. O10, P22

Schirhagl, R. O11, P9

Schmitt, C.A. O4

Schreier, S. O3, P23

Schuhmacher, R. O14

Schulte-Hermann, R. O8

Schwartz, H. P5

Seidler, K. O11, P9

Seifner, A. O11, P9

Siebenhandl-Ehn, S. P24

Solar, S. P1

Sontag, G. P4, P5, P6

Sturtzel, B. O18

Swoboda, S. O10

Thaler, R. O7

Tramp, I. P25

\section{Unger, F.M. O16}

Viernstein, H. O16

Wagner, K.-H. O2, P10, P12, P18, P19, P20

Wagner, V. O10

Weippl, A. P16

Windisch, W. O10, P22

Wortuba, F. P26

Zemann, A. P27

\section{KARGER}

(C) 2008 S. Karger AG, Basel

Fax +4161306 1234

E-Mail karger@karger.ch

www.karger.com

Accessible online at:

www.karger.com/anm 